\title{
Integration of refugees into routine primary care in NSW, Australia
}

\author{
Mark F Harrisa,a,b \\ a Centre for Primary Health Care and Equity, Faculty of Medicine, UNSW Sydney, Australia \\ b Guest Editor, Public Health Research \& Practice, Issue 1, 2018 \\ c Corresponding author: m.f.harris@unsw.edu.au
}

\section{Article history}

Publication date: March 2018

Citation: Harris M. Integration of

refugees into routine primary care in NSW, Australia. Public Health Res Pract. 2018;28(1):e2811802. https://doi.org/10.17061/phrp2811802

\section{Key points}

- Current settlement arrangements in Australia can lead to refugees missing out on healthcare that comprehensively meets their needs

- Greater integration is required between specialised refugee health services and primary care, including improved communication between providers and better transition of care between services

\section{Abstract}

Refugees have complex physical, psychological and social needs that are challenging to manage comprehensively in primary care. In recent years, many refugees settling in Australia have been sponsored by family members. Although they may receive settlement support, these new arrivals may not be assessed or managed by specialised refugee health services. Their sponsors usually link them to bilingual general practitioners, but these doctors may not be aware of or have access to a comprehensive range of services. There is an urgent need for more integrated health service provision for people from refugee backgrounds, based on trust and communication. This requires change at the practice, local service and system level.

\section{Background}

About 140000 refugees were accepted as humanitarian entrants by Australia during the 10 years between 2006 and 2015. ${ }^{1}$ There were also about 29000 people claiming asylum at the end of 2016 . Although these individuals represent less than $1 \%$ of the population, they are a significant group for primary care providers working in certain regions. People from refugee backgrounds have complex health and social care needs. Their problems are associated with risks, exposures, trauma and economic hardship in their countries of origin, during transit and, in some cases, while in detention. Once they are living in the community in Australia, they may suffer from uncertainty, discrimination and reduced access to healthcare because of language, cultural, political, social, administrative and legal barriers. ${ }^{2}$

Refugees and asylum seekers often experience mental health problems associated with their migration experience, including anxiety, depression and post-traumatic stress disorder. These may be particularly challenging to manage, especially if there are language and cultural differences between provider and patient. ${ }^{3}$ There may also be family issues associated with separation, acculturation or generational conflict. Refugees also frequently suffer from chronic long-term physical conditions such as cardiovascular disease and diabetes, because of both the increased prevalence of these conditions globally, and of lifestyle and other risk factors during their migration. ${ }^{4}$ 
In the past few years, many resettled refugees have been sponsored. This means that, although they can receive resettlement support, they may not be formally assessed or managed by specialised refugee health services. They may, instead, be assisted to attend a general practitioner (GP) known to the sponsor. Although this can help to ensure that patients see a GP who speaks their language, it may also place a significant burden on the GP to not only provide healthcare but also support patients' legal and administrative needs. ${ }^{5}$ GPs may be unaware of all the supports available from government and nongovernment agencies. Other staff within or linked to the practice (e.g. administrative, nursing or allied health staff) may struggle to deal with refugees' health issues because they may lack the language, knowledge or skills required.

\section{Specialised services}

Specialised refugee health services exist in each Australian state. The NSW Refugee Health Service, for example, aims to promote the health of people from a refugee background living in New South Wales (NSW) by assisting the refugees and the health professionals who work with them. ${ }^{6}$ The service provides initial health assessments and health promotion to refugees, as well as referrals and linkages to other services, and education and support for health professionals. Organisations like the NSW Service for the Treatment and Rehabilitation of Torture and Trauma Survivors (STARTTS) ${ }^{7}$ and nongovernment organisations (NGOs) such as the Asylum Seekers Centre ${ }^{8}$ in Sydney provide targeted health services and other assistance for refugees and asylum seekers. The demand for these services varies greatly and is affected by government policies that govern pathways for humanitarian entrants as well as the size of the annual refugee intake, asylum seeker eligibility for healthcare and availability of other services. NGOs in particular are often constrained by limited resources.

\section{Primary care providers}

Most primary care and specialised health personnel working with refugees have a high degree of commitment. Because of the nature of the physical and psychological problems faced by refugees, a multidisciplinary team approach is acknowledged as essential. ${ }^{9}$ However, many primary care providers feel isolated and frustrated by a lack of coordination. ${ }^{10}$ Refugee and asylum seeker patients attending general practice providers may miss out on a comprehensive assessment and access to health services that can assist with their often complex problems. ${ }^{11}$ Similarly, those attending specialised refugee services may, despite the best efforts of these organisations, receive poor continuity of care over time as they seek to engage with mainstream primary care. ${ }^{12}$

\section{Integrated care}

So where does all this leave us? How can we achieve primary health care goals and implement for refugees what the World Health Organization has recommended: "well-planned, integrated health services required to best respond to their health needs across their lifetime and ensure that necessary services reach the most vulnerable"? ${ }^{13}$ Refugees need support from a comprehensive range of services and providers that share a common understanding of the patient's context, needs and pathways to recovery. With the best intentions, fragmented care can lead to missed opportunities for prevention and early intervention, and this may result in poor outcomes.

Integrated care starts with a shared need to work together. Primary care providers need support to deal with the complexity of physical, psychological and social problems faced by refugees. Specialised services need a way to reach out to sponsored refugees and to transition these refugees to long-term comprehensive primary care. More integrated care also requires trust based on knowledge of each other's role and a relationship built over time. This can be achieved with the help of effective communication tools (such as shared assessments and care plans), through practice visits by refugee health staff to facilitate more comprehensive and appropriate care (including use of interpreters and links to community services), and the use of community or peer workers to support refugees in their care transitions and to attend referral services. ${ }^{12}$

Change at the practice and local system levels is necessary to provide the capacity for integrated care. This capacity includes the same sorts of elements that make up the chronic care model: information systems (which identify refugees and facilitate sharing information), decision support (to assist in the assessment and management of complex problems), multidisciplinary teamwork (to provide comprehensive care), selfmanagement support (for prevention and management of chronic conditions) and links to community resources (especially refugee community organisations, which can help improve refugees' health literacy and address problems associated with settlement and acculturation).

At the local level, more integrated refugee healthcare requires collaboration between primary health networks and both government and nongovernment refugee health services. Integration between general practice and state-funded community health and hospital services is a significant challenge in the whole Australian health system. It is even more complex in refugee healthcare because of the additional transitions and discontinuities between national and state agencies, the public and private sectors, and the health and welfare sectors. Refugees are particularly vulnerable to fragmented care because of the nature of their health and social problems and their lack of understanding of the Australian health system. This may lead to increased health expenditure in the long run. ${ }^{14}$ In Australia, we should be able to do better. 


\section{Competing interests}

$\mathrm{MH}$ is a volunteer medical officer at the Asylum Seekers Centre and a board member of the Central and Eastern Sydney Primary Health Network.

\section{Author contributions}

$\mathrm{MH}$ is the sole author.

\section{References}

1. Parliament of Australia. Refugee resettlement to Australia: what are the facts? Canberra: Australian Government; 2016 [cited 2018 Jan 18]. Available from: www.aph.gov.au/About_Parliament/Parliamentary_ Departments/Parliamentary_Library/pubs/rp/rp1617/ RefugeeResettlement.

2. NSW Refugee Health Service. Refugees in NSW: an overview. Sydney: NSW Refugee Health Service; 2018 [cited 2018 Jan 18]. Available from: www.swslhd.health.nsw.gov.au/refugee/pdf/Resource/ FactSheet/FactSheet_01.pdf

3. Kirmayer LJ, Narasiah L, Munoz M, Rashid M, Ryder AG, Guzder J, et al. Common mental health problems in immigrants and refugees: general approach in primary care. CMAJ. 2011;183(12):E959-67.

4. Yun K, Hebrank K, Graber LK, Sullivan M-C Chen I, Gupta J. High prevalence of chronic noncommunicable conditions among adult refugees: implications for practice and policy. J Community Health. 2012;37(5):1110-8.

5. Bowers EJ, Cheng I. Meeting the primary health care needs of refugees and asylum seekers. Adelaide: Primary Health Care Research and Information Service, Flinders University; 2010 [cited 2017 Dec 1]. Available from: dspace.flinders.edu.au/xmlui/bitstream/ handle/2328/26612/RRU\%20Dec\%202010. pdf?sequence $=1$ \&isAllowed $=y$
6. NSW Ministry of Health. NSW Refugee Health Service Sydney: NSW Government. 2016 [cited 2018 Jan 18]. Available from: www.swslhd.health.nsw.gov.au/refugee/

7. STARTTS. NSW Service for the Treatment and Rehabilitation of Torture and Trauma Sufferers (STARTTS) Sydney: STARTTS; 2016 [cited 2018 Jan 18]. Available from: www.startts.org.au/

8. Asylum Seekers Centre. Asylum Seekers Centre Sydney: ASC; 2017 [cited 2018 Jan 18]. Available from: www.asylumseekerscentre.org.au

9. Royal Australian College of General Practitioners. RA16 - Refugee and asylum seeker health contextual unit. Melbourne: RACGP; 2016 [cited 2017 Dec 1]. Available from: www.racgp.org.au/Education/Curriculum/Refugeeand-asylum-seeker-health

10. Farley R, Askew D, Kay M. Caring for refugees in general practice: perspectives from the coalface. Aust J Prim Health. 2014;20(1):85-91.

11. Mirza M, Luna R, Mathews B, Hasnain R, Hebert E, Niebauer A, Mishra UD. Barriers to healthcare access among refugees with disabilities and chronic health conditions resettled in the US Midwest. J Immigr Minor Health. 2014;16(4):733-42.

12. Joshi C, Russell G, Cheng IH, Kay M, Pottie K, Alston M, et al. A narrative synthesis of the impact of primary health care delivery models for refugees in resettlement countries on access, quality and coordination. Int J Equity Health. 2013;12(1):88.

13. World Health Organisation. WHO global strategy on people-centred and integrated health services. Geneva: WHO; 2015 [cited 2018 Jan 18]. Available from: www.who.int/servicedeliverysafety/areas/people-centredcare/global-strategy/en/

14. Bozorgmehr K, Razum O. Effect of restricting access to health care on health expenditures among asylumseekers and refugees: a quasi-experimental study in Germany, 1994-2013. PLoS One. 2015;10(7):e0131483.

\section{Copyright: (c) (i) (2)}

(C) 2018 Harris. This article is licensed under the Creative Commons Attribution-NonCommercial-ShareAlike 4.0 International Licence, which allows others to redistribute, adapt and share this work non-commercially provided they attribute the work and any adapted version of it is distributed under the same Creative Commons licence terms. See: www.creativecommons.org/licenses/by-nc-sa/4.0/ 